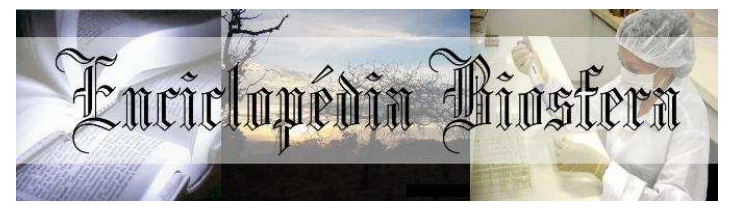

\title{
AVALIAÇÃO DO USO DE REGRESSÃO E REDE NEURAL ARTIFICIAL PARA MODELAGEM DO AFILAMENTO DO FUSTE DE EUCALIPTO EM SISTEMA SILVIPASTORIL
}

Simone Silva ${ }^{1}$, Sílvio Nolasco de Oliveira Neto ${ }^{2}$, Helio Garcia Leite ${ }^{3}$, Amana de Magalhães Matos Obolari ${ }^{4}$, Bruno Leão Said Schettini ${ }^{5}$

Engenheira Florestal, Mestranda em Ciências Florestais, Programa de PósGraduação da Universidade Federal de Viçosa, Viçosa, MG, Brasil.

(simone.silva.ufv@gmail.com)

2 Engenheiro Florestal, Prof. Doutor em Ciências Florestais, UFV, Universidade Federal de Viçosa, Departamento de Engenharia Florestal, DEF/UFV, Viçosa, MG, Brasil.

${ }^{3}$ Engenheiro Florestal, Prof. Doutor em Ciências Florestais, UFV, Universidade Federal de Viçosa, Departamento de Engenharia Florestal, DEF/UFV, Viçosa, MG, Brasil.

${ }^{4}$ Engenheira Florestal, Mestranda em Ciências Florestais, Programa de PósGraduação da Universidade Federal de Viçosa, Viçosa, MG, Brasil.

${ }^{5}$ Engenheiro Florestal, Mestrando em Ciências Florestais, Programa de PósGraduação da Universidade Federal de Viçosa, Viçosa, MG, Brasil

Recebido em: 08/04/2016 - Aprovado em: 30/05/2016 - Publicado em: 20/06/2016 DOI: 10.18677/Enciclopedia_Biosfera_2016_018

\section{RESUMO}

O objetivo deste estudo foi avaliar a eficiência do uso de uma rede neural artificial (RNA) para estimar o afilamento do fuste de árvores de eucalipto em sistemas silvipastoris com dois arranjos espaciais. Os dados foram provenientes de 35 árvores-amostras cubadas em sistemas silvipastoris com arranjos espaciais de $12 \mathrm{~m}$ x $4 \mathrm{~m} \mathrm{e} 12 \mathrm{~m}$ x $2 \mathrm{~m}$. Foi ajustado o modelo proposto por Garay para cada arranjo espacial. Foi treinada uma RNA de configuração Multilayer Perceptron utilizando os arranjos como variável categórica. As demais variáveis de entrada da RNA foram o diâmetro à altura do peito - 1,30 $\mathrm{m}$ de altura, altura total, alturas de cada seção e os correspondentes diâmetros. A precisão dos métodos foi avaliada por meio das estatísticas da raiz do erro quadrático médio, correlação entre diâmetros observados e estimados, dispersão dos erros percentuais e o desvio médio absoluto. A RNA apresentou desempenho similar ao das duas funções de afilamento, demonstrando ser uma metodologia apropriada para pequenos plantios de eucalipto em sistema silvipastoril, onde pode existir restrição para o abate de árvores.

PALAVRAS-CHAVE: ILPF, inteligência artificial, taper. 


\title{
EVALUATION OF THE USE OF REGRESSION AND ARTIFICIAL NEURAL NETWORK FOR MODELLING STEM TAPER EUCALYPT IN A SILVOPASTORAL SYSTEM
}

\begin{abstract}
The aim of this study was to evaluate the efficiency of using an artificial neural network (ANN) to estimate the stem taper of eucalypt trees in a silvopastoral system composed with two spatial arrangements. The data used were collected out of 35 sample-trees scaled in a silvipastoral system with spatial arrangements of $12 \mathrm{~m} \times 4 \mathrm{~m}$ and $12 \mathrm{~m} \times 2 \mathrm{~m}$. The taper model proposed by Garay was fitted for each spatial arrangement. Also, the ANN with Multilayer Perceptron configuration, using the spatial arrangement as a categorical variable, was trained. The others input variables for the ANN were the diameter at breast height - $1.30 \mathrm{~m}$ height, total height, height of each section and the corresponding diameters. The accuracy of the methods was evaluated using the Root Mean-square Error, the correlation between observed and estimated diameters, dispersion of percentage errors and the mean absolut deviaton. The ANN achieved a similar performance compared to the two functions of tapering, proving to be an appropriate methodology for small eucalyptus plantations in silvopastoral system, where there may be restrictions for logging.
\end{abstract}

KEYWORDS: Integrated crop-livestock-forest, artificial intelligence, taper.

\section{INTRODUÇÃO}

A região da Zona da Mata mineira é caracterizada pela predominância de pequenas propriedades rurais, cuja principal fonte de renda é a pecuária convencional. Entretanto, essa prática é a principal causa da degradação das pastagens e, consequentemente, da diminuição da capacidade produtiva da terra (FREITAS et al., 2013).

Uma alternativa ao uso intensivo do solo consiste na implantação de sistemas agroflorestais (SAF), a exemplo dos sistemas agrossilvipastoris e silvipastoris, os quais tem como vantagem a recuperação da produtividade nessas áreas (FREITAS et al., 2013). Outra característica de tais sistemas é o fato de que os mesmos podem gerar maior ganho financeiro aos produtores quando as árvores são destinadas aos multiprodutos (SILVEIRA et al., 2011).

A agrossilvicultura com eucalipto pode ser considerada como uma opção sustentável para o desenvolvimento florestal na Zona da Mata, uma vez que possibilita a fixação de carbono da atmosfera, a proteção do solo, a regulação do regime hídrico, o aumento da diversidade de espécies e a geração de empregos (VALE et al., 2004), além de promover o conforto animal através da melhoria do microclima do pasto (GARCIA et al., 2011).

Apesar do interesse pela implantação de sistemas silvipastoris na Zona da Mata mineira, estudos sobre modelagem visando estimar volume de madeira ainda são escassos (MÜLLER et al., 2014). Dentre os poucos trabalhos encontrados na literatura pertinente em relação à dados oriundos de SAF, destacam-se os de FONTAN et al. (2011), SILVEIRA et al. (2011) e SALLES et al. (2012). Tais estudos foram conduzidos com dados de sistemas agrossilvipastoris localizados na região Noroeste do estado de Minas Gerais. Apesar da qualidade dos trabalhos realizados, as equações obtidas nesses estudos não podem ser aplicadas em outros SAFs encontrados na Zona da Mata, devido às diferenças nos arranjos espaciais e na capacidade produtiva. 
Com relação à utilização de modelos para estimação de multiprodutos (SOUZA et al., 2007) com emprego de modelos de afilamento do fuste (CAMPOS \& LEITE, 2013), os trabalhos utilizando dados de SAF são ainda mais escassos, sendo o de maior destaque aquele realizado por MÜLLER et al. (2014). Nesse, o foco foi o ajuste de equações para estimativa de altura, volume e afilamento do fuste em um sistema silvipastoril composto por eucalipto e acácia, localizado na Zona da Mata mineira.

O afilamento do fuste pode ser modelado empregando equações de regressão (CAMPOS \& LEITE, 2013) ou redes neurais artificiais (RNA) (LEITE et al., 2011). Em ambos os casos, não é necessária grande quantidade de dados de árvores-amostra, bastando que haja representatividade dos diferentes portes de árvores existentes. Tal característica é importante para o caso de pequenas propriedades, nas quais nem sempre é possível realizar o abate de muitas árvores no campo para obtenção de dados de cubagem rigorosa. Com poucas e representativas árvores-amostra, é possível obter equações ou redes neurais artificiais que resultam em estimativas da forma do fuste com grande exatidão (MENDONÇA et al., 2015).

Em termos de equações de regressão, existem diferentes modelos de afilamento, sendo os mais utilizados aqueles desenvolvidos por KOZAK et al. (1969), DEMAERSCHALK (1972), BALDWIN (1991), ORMEROD (1973) e GARAY (1979), dentre outros. Esse último tem sido empregado para diferentes espécies, gerando estimativas de grande exatidão (LEITE et al., 2006; LEITE et al., 2011; SILVA et al., 2011). Já com relação às redes neurais artificiais, diversos estudos envolvendo aproximação de funções em manejo florestal foram desenvolvidos (GÖRGENS et al., 2009; SOARES et al., 2011; BINOTI et al., 2012; ÖZÇELIK et al., 2013; GÖRGENS et al., 2014; BINOTI et al., 2014; DIAMANTOPOULOU et al., 2015). Para o caso específico da modelagem do perfil do fuste, destacam-se os trabalhos de SCHIKOWSKI et al. (2015) e MENDONÇA et al. (2015).

Devido à importância da estimação do afilamento do fuste e da ausência de equações específicas para a Zona da Mata mineira, justifica-se a elaboração de trabalhos avaliando diferentes métodos de estimativa do perfil do fuste para dados de sistemas agroflorestais. Assim, o presente estudo foi conduzido de modo a ajustar um modelo de afilamento do fuste para árvores de eucalipto em sistemas com dois arranjos espaciais e comparar as estimativas obtidas com uma rede neural artificial.

\section{MATERIAL E MÉTODOS}

Foram utilizados dados provenientes de povoamentos de eucalipto em sistema silvipastoril, localizados no município de Viçosa, Minas Gerais. O plantio foi realizado em dezembro de 2007 com arranjos espaciais de $12 \mathrm{~m} \times 2 \mathrm{~m}$ e $12 \mathrm{~m} \times 4$ $\mathrm{m}$.

Aos 96 meses de idade, foram abatidas e cubadas 35 árvores-amostra, sendo 20 árvores para o espaçamento $12 \mathrm{~m} \times 2 \mathrm{~m}$ e 15 árvores no espaçamento $12 \mathrm{~m} \times 4$ $\mathrm{m}$. O menor número de árvores no espaçamento $12 \mathrm{~m} \times 4 \mathrm{~m}$ foi devido à menor amplitude observada na distribuição dos diâmetros a 1,3 $\mathrm{m}$ de altura (dap) das árvores em relação ao espaçamento $12 \mathrm{~m} \times 2 \mathrm{~m}$.

Foram medidos os diâmetros nas alturas de $0,1 \mathrm{~m}, 0,3 \mathrm{~m}, 0,7 \mathrm{~m}, 1,0 \mathrm{~m}$ e 1,3 $\mathrm{m}$ (posição do dap). A partir da altura de $1,3 \mathrm{~m}$ até a altura cujo diâmetro fosse igual a 7,0 cm (diâmetro comercial), os diâmetros foram medidos a cada 1,0 m. 
Os dados obtidos na cubagem foram inicialmente empregados para ajuste do modelo de afilamento proposto por GARAY (1979) (Modelo 1). Os parâmetros do modelo foram obtidos pelo método de mínimos quadrados, utilizando-se o algoritmo Gauss-Newton (STATSOFT, 2016), assim proposto:

$$
d=\operatorname{dap} \beta_{0}\left(1+\beta_{1} \operatorname{Ln}\left(1-\beta_{2} h^{\beta_{3}} H^{-\beta_{3}}\right)\right)+\varepsilon
$$

Em que:

$\mathrm{d}=$ diâmetro sem casca, em $\mathrm{cm}$, na altura h;

dap = diâmetro com casca na altura $1,3 \mathrm{~m}$, em cm;

$\mathrm{h}=$ distância do nível do terreno até o diâmetro $\mathrm{d}$, em $\mathrm{m}$;

$\mathrm{H}=$ altura total da árvore, em $\mathrm{m}$;

$\beta_{0}, \beta_{1}, \beta_{2}, \beta_{3}=$ parâmetros do modelo; e

$\varepsilon=$ erro aleatório.

Foi utilizado o teste de identidade proposto por Leite \& Oliveira (2002) para confirmar a necessidade de uso de ajustes específicos do modelo de Garay para cada arranjo espacial. A hipótese nula do teste é $\mathrm{H}_{0}$ : não existe diferença significativa entre uma equação geral e equações específicas por arranjos espaciais.

Foi treinada uma rede neural artificial (RNA) considerando $70 \%$ do conjunto de dados obtidos pela cubagem rigorosa, sendo os demais $30 \%$ utilizados para validação do treinamento realizado. A escolha dos dados de cada grupo foi feita aleatoriamente pelo software utilizado, neste caso o Neuroforest $\mathbb{B} 3.3$ (www.neuroforest.ucoz.com).

A RNA utilizada foi do tipo perceptrons de múltiplas camadas, conhecida como Multilayer Perceptron (MLP), sendo o algoritmo de treinamento escolhido o Resilient Propagation. Utilizou-se o dap, a altura total, os diâmetros ao longo do fuste e suas respectivas posições como variáveis contínuas de entrada. $O$ espaçamento foi utilizado como variável categórica. Na camada oculta foram considerados três neurônios, sendo tal valor dado pela média entre a quantidade de neurônios das camadas de entrada e de saída da rede neural. A função de ativação considerada foi a sigmoidal.

A avaliação dos métodos utilizados considerando cada espaçamento foi realizada com base nas estatísticas raiz quadrada do erro quadrático médio (RQEM) (Equação 2), bias (Equação 3), correlação entre diâmetros observados e estimados $\left(r_{y \hat{y}}\right)$ (Equação 4) e a média dos desvios absolutos (Equação 5). Ainda, foram analisados gráficos de dispersão dos erros percentuais e histograma de frequência dos erros percentuais.

$$
\begin{aligned}
& \text { RQEQM } \%=\frac{100}{\bar{Y}} \sqrt{\frac{\sum_{i=1}^{n}\left(Y_{i}-\hat{Y}_{i}\right)^{2}}{n}} \\
& \text { Bias }=n^{-1} \sum_{i=1}^{n}\left(Y_{i}-\hat{Y}_{i}\right) \\
& r_{y y}=\frac{\operatorname{cov}\left(Y_{i-} \hat{Y}_{l}\right)}{\sqrt{\operatorname{var}\left(Y_{1}\right) \operatorname{var}\left(\hat{Y}_{1}\right)}} \\
& D M A=\frac{\sum_{i=1}^{n} \mid\left(Y_{i}-\hat{Y}_{i} \mid\right.}{n}
\end{aligned}
$$

Em que: 
$\bar{Y}=$ média dos valores observados;

$\mathrm{n}=$ número total de dados observados;

$\widehat{Y}_{i}=$ valor do i-ésimo diâmetro estimado;

$\mathrm{Y}_{i}=$ valor do i-ésimo diâmetro observado;

cov = covariância; e

var $=$ variância.

\section{RESULTADOS E DISCUSSÃO}

O resultado do teste de identidade realizado mostrou que a hipótese de nulidade pode ser rejeitada, a $5 \%$ de probabilidade (Tabela 1). Dessa maneira, pode-se considerar que existe diferença estatisticamente significativa entre os valores estimados pela equação geral e os valores estimados por equações especificas para cada arranjo espacial. Tal resultado corrobora para a necessidade de se ajustar equações de afilamento diferentes para cada espaçamento, o que é reforçado pela constatação feita por Nogueira et al. (2008), onde os autores afirmaram que o afilamento do fuste das árvores é afetado pelo espaçamento do plantio.

TABELA 1: Resultados obtidos com o procedimento estatístico

\begin{tabular}{cc}
\hline Estatística & Valor \\
\hline $\mathrm{F}(\mathrm{Ho})=$ & $37,03^{\star}$ \\
$\mathrm{t}(\mathrm{e})=$ & $2,94^{\star}$ \\
$r_{y i y 1} \geq 1-|\bar{e}|$ & $\mathrm{Sim}$ \\
Erro médio (e) & $-0,002$ \\
\hline Resultado & $\neq$ \\
\hline
\end{tabular}

Ao analisar os valores das estatísticas de avaliação dos resultados obtidos (Tabela 2), pode-se observar que tanto a rede neural artificial quanto as regressões apresentaram desempenhos similares para os dois espaçamentos, com elevados valores de correlação e com valores de bias e raiz quadrada do erro quadrático médio e desvio médio absoluto próximos a zero. Mendonça et al. (2015), ao estimarem o diâmetro do fuste de eucalipto utilizando RNA e um polinômio do quinto grau, também encontraram valores estatísticos próximos a zero para ambos os métodos.

TABELA 2: Estatística de avaliação da RNA dos modelos de Garay ajustados a dados de eucalipto em sistema silvipastoril com arranjos espaciais $12 \mathrm{~m} \times 2 \mathrm{~m}$ e $12 \mathrm{~m} \times 4 \mathrm{~m}$

\begin{tabular}{cccccc}
\hline Método & Espaçamento & $\mathrm{r}_{\text {ŷิ }}$ & RQEQM \% & bias & DMA \\
\hline \multirow{2}{*}{ RNA } & $12 \mathrm{~m} \times 2 \mathrm{~m}$ & 0,9795 & 7,26 & 0,0325 & 0,97 \\
& $12 \mathrm{~m} \times 4 \mathrm{~m}$ & 0,9846 & 7,28 & $-0,0198$ & 1,08 \\
\hline \multirow{2}{*}{ Regressão } & $12 \mathrm{~m} \times 2 \mathrm{~m}$ & 0,9761 & 7,98 & 0,1029 & 1,12 \\
& $12 \mathrm{~m} \times 4 \mathrm{~m}$ & 0,9845 & 7,32 & 0,0824 & 1,11 \\
\hline
\end{tabular}

Ainda, em relação à Tabela 2, pode-se notar que os valores obtidos com a utilização da rede neural artificial foram ligeiramente melhores que os obtidos pela utilização de equações de regressão. Tal constatação é interessante no sentido de 
que o treinamento de apenas um RNA para todos os dados é menos trabalhosa que o ajuste de uma regressão para cada espaçamento.

Observando os histogramas e os gráficos de dispersão de resíduos obtidos pelo uso da rede neural (Figuras 1 e 2) e da regressão, pode-se notar que ambas as técnicas apresentaram a maior parte dos resíduos concentrados entre $-20 \%$ e $20 \%$. Tal amplitude é comumente observada em trabalhos com utilização de redes neurais artificiais, bem como de modelos de afilamento para estimativa de diâmetros ao longo do fuste.
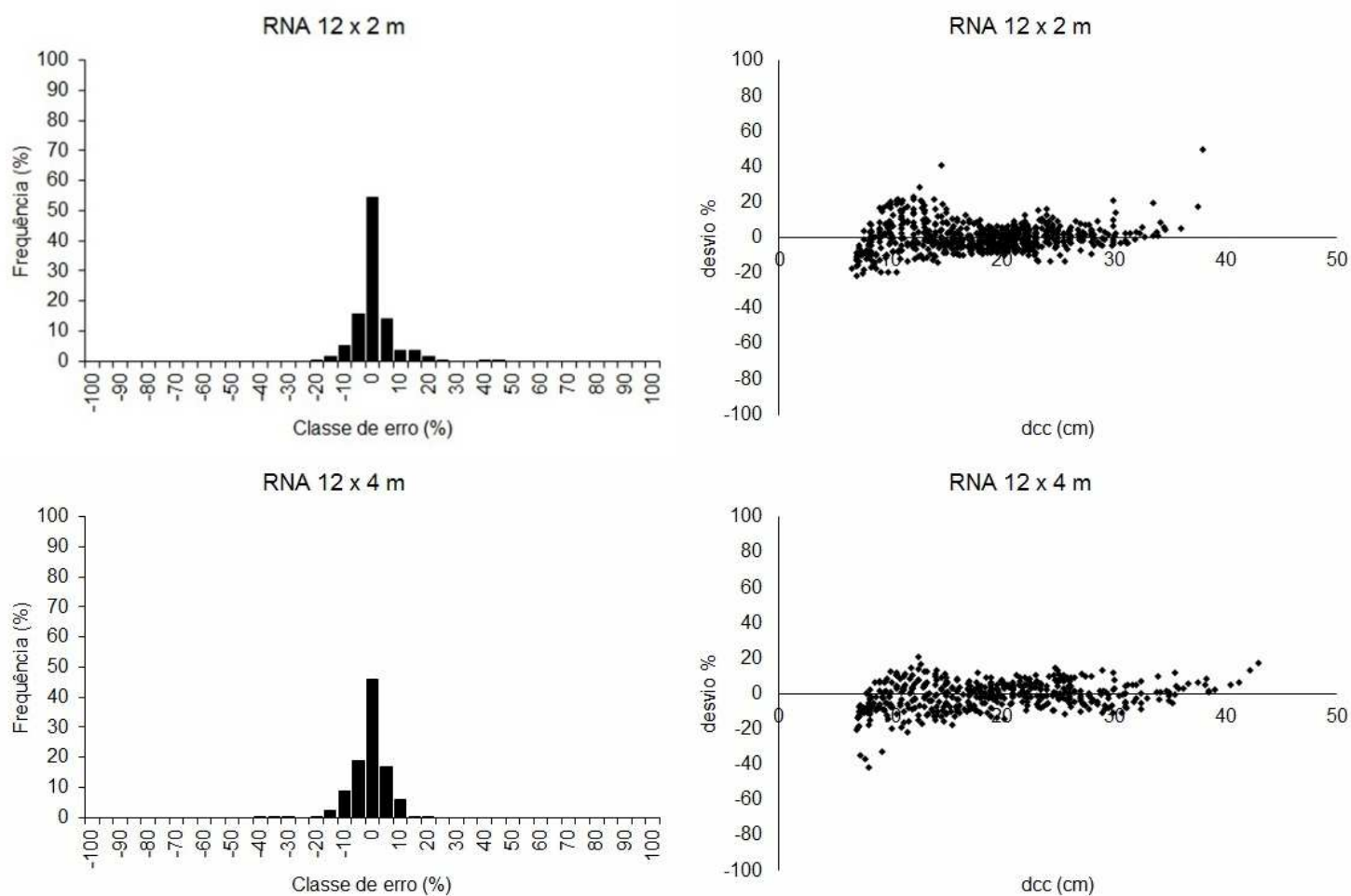

FIGURA 1: Histogramas e gráficos de dispersão de resíduos das estimativas de diâmetro para os arranjos espaciais $12 \mathrm{~m} \times 2 \mathrm{~m}$ e $12 \mathrm{~m} \times 4 \mathrm{~m}$ obtidas com emprego de uma RNA, treinada com dados em sistema silvipastoril. Fonte: os autores. 

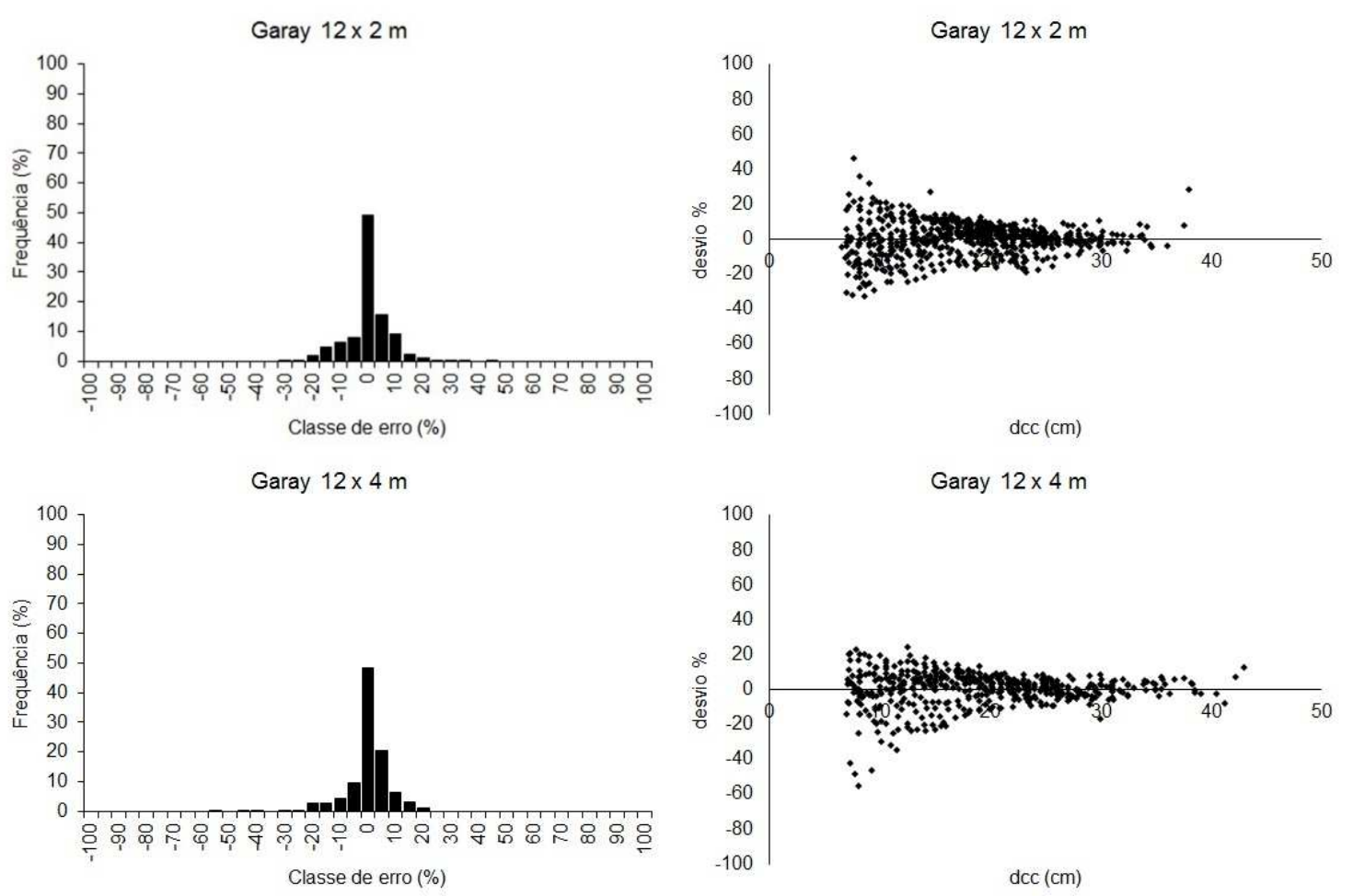

FIGURA 2: Gráficos de dispersão de resíduos das estimativas de diâmetro para os arranjos espaciais $12 \mathrm{~m} \times 2 \mathrm{~m}$ e $12 \mathrm{~m} \times 4 \mathrm{~m}$ obtidas com emprego do modelo de Garay, ajustados com dados em sistema silvipastoril. Fonte: os autores.

A análise dos gráficos de dispersão para os dois espaçamentos demonstra que as equações ajustadas referentes aos modelos de Garay foram semelhantes em termos de qualidade do ajustamento. Contudo, para ambos os espaçamentos, houveram uma maior dispersão de resíduos para valores menores de diâmetro. Resultados que envolvem certa dificuldade em estimar os menores diâmetros também foram encontrados em alguns trabalhos envolvendo tanto os modelos de regressão quanto redes neurais artificiais, como observado em Leite et al. (2011), MÜLLER et al. (2014) e SCHIKOWSKI et al. (2015).

Apesar da quantidade relativamente pequena de árvores-amostras, a variabilidade, em termos de dap, altura e forma do fuste existente nos dados, foi suficiente para o treinamento da rede neural. Sistemas silvipastoris são caracterizados por possuírem arranjos espaciais mais amplos, isso contribuiu para a maior variação nos dados mensurados.

SCHIKOWSKI et al. (2015) encontraram resultados semelhantes aos obtidos no presente estudo, utilizando dados de 47 árvores de eucalipto para treino e validação de uma RNA. Esses autores observaram desempenhos semelhantes entre as redes neurais e modelos de Hradetzky e Garay.

VENDRUSCOLO et al. (2015) compararam regressão não linear e redes neurais artificiais para estimar a altura de povoamentos de eucalipto e obtiveram desempenho semelhante para ambos os métodos. Os autores mencionaram a vantagem de se adicionar variáveis categóricas e explicativas, tendo as mesmas contribuído para uma boa precisão das estimativas geradas pela RNA.

A rede treinada selecionada neste estudo, além de ter explicado a variação nos dados de ambos os arranjos espaciais, foi tão precisa quanto a regressão, em termos de correlação, raiz quadrada do erro quadrático médio e bias. Ademais, a rede permitiu diferenciar o afilamento do fuste entre os arranjos espaciais. 


\section{CONCLUSÃO}

A rede neural artificial selecionada apresenta desempenho similar aos modelos de Garay para ambos os espaçamentos, demonstrando ser uma metodologia apropriada para pequenos plantios de eucalipto em sistema silvipastoril, onde pode existir restrição para o abate de árvores.

\section{REFERÊNCIAS}

BALDWIN JR., V. C.; FEDUCCIA, D. P. Compatible Tree-volume and upper-stem diameter equations for plantation Loblolly Pines in the West Gulf region. South. Journal Applied Forestry, v. 15, n.2, p. 92-97, 1991. Disponível em: $<$ http://www.ingentaconnect.com/content/saf/sjaf/1991/00000015/00000002/art00007 $>$.

BINOTI, D. H. B.; BINOTI, M. L. M. S.; LEITE, H. G. Configuração de redes neurais artificiais para estimação do volume de árvores. Ciência da Madeira, v. 5, n. 1, p. 58-67, 2014. Disponível em: <http://dx.doi.org/10.12953/2177-6830.v05n01a06>. doi: 10.12953/2177-6830.v05n01a06.

BINOTI, D. H. B.; BINOTI, M. L. M. S.; LEITE, H. G. Redução dos custos em inventário de povoamentos equiâneos utilizando redes neurais artificiais. Agrária, v. 8, p. 125-129, 2012. Disponível em: <http://dx.doi.org/10.1590/S0100$\underline{67622013000400007>}$. doi:10.5039/agraria.v8i1a2209.

CAMPOS, J. C. C.; LEITE, H. G. Mensuração florestal: perguntas e respostas. 4. ed. Viçosa: UFV, 2013. 548 p.

DEMAERSCHALK, J. P. Converting volume equations to compatible taper equations. Forest Science, v. 18, n. 3, p. 241-245, 1972 . Disponível em: $<$ http://www.ingentaconnect.com/content/saf/fs/1972/00000018/00000003/art00018>.

DIAMANTOPOULOU, M. J.; OZÇELIK, R.; CRECENTE-CAMPO, F.; ELER, U. Estimation of Weibull function parameters for modelling tree diameter distribution using least squares and artificial neural networks methods. Biosystems Engineering, v. 133, p. 33-45, 2015. Disponível em: $<$ http://dx.doi.org/10.1016/j.biosystemseng.2015.02.013>. doi:10.1016/j.biosystemseng.2015.02.013

FONTAN, I. C. I.; REIS, G. G.; REIS, M. G. F.; LEITE, H. G.; MONTE, M. A.; RAMOS, D. C.; SOUZA, F. C. Growth of pruned eucalypt clone in an agroforestry system in southeastern Brazil. Agroforestry Systems, v. 83, n. 2, p. 121-131, 2011. Disponível em: <http://dx.doi.org/10.1007/s10457-011-9432-1>. doi:10.1007/s10457011-9432-1

FREITAS, E. C. S.; OLIVEIRA NETO, S. N.; FONSECA, D. M.; SANTOS, M. V.; LEITE, H. G.; MACHADO, V. D. Deposição de serapilheira e de nutrientes no solo em sistema agrossilvipastoril com eucalipto e acácia. Revista Árvore, v. 37, n. 3, p. 409-417, 2013. Disponível em: <http://dx.doi.org/10.1590/S0100-

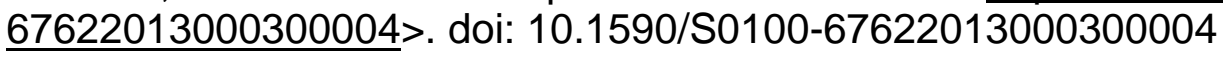

GARAY, L. Tropical forest utilization system. VIII. A taper model for entire stem 
profile including buttressing. Seatlhe: Coll. Forest. Resour, Inst. Forest Prod. Univ. Wash., 1979. 64 p. Disponível em: <http://www.amazon.co.uk/entire-profile-includingbuttressing-Tropical/dp/B0006XEM9G>.

GARCIA, A. R.; MATOS, L. B.; JÚNIOR, J. B. L.; NAHÚM, B. S.; ARAÚJO, C. V.; SANTOS, A. X. Variáveis fisiológicas de búfalas leiteiras criadas sob sombreamento em sistemas silvipastoris. Pesquisa Agropecuária Brasileira, v. 46, p. 1409-1414, 2011. Disponível

em: $<$ http://seer.sct.embrapa.br/index.php/pab/article/view/8628/6658>.

GÖRGENS, E. B.; LEITE, H. G.; SANTOS, H. N.; GLERIANI, J. M. Estimação do volume de árvores utilizando redes neurais artificiais. Revista Árvore, v. 33, n. 6, p. 1141-1147, 2009. Disponível em:

<http://dx.doi.org/10.1590/S010067622009000600016>.

doi:

$10.1590 /$ S010067622009000600016

GÖRGENS, E. B.; LEITE, H. G.; GLERIANI, J. M.; SOARES, C. P. B.; CEOLIN, A. Influência da arquitetura na estimativa de volume de arvores individual por meio de redes neurais artificiais. Revista Árvore, v. 38, n. 2, p. 289-295, 2014. Disponível em: <http://dx.doi.org/10.1590/S0100-67622014000200009>. doi: 10.1590/S010067622014000200009.

KOZAK, A.; MUNRO, D. D.; SMITH, J. H. G. Taper functions and their application in Forest inventory. Forestry Chronicle, v. 45, n. 4, p. 278-283, 1969. Disponível em: <http://pubs.cif-ifc.org/doi/abs/10.5558/tfc45278-4>. doi: 10.5558/tfc45278-4

LEITE, H. G.; OLIVEIRA, F. H. T. Statistical procedure to test the indentity between of analytical methods. Communications in soil science and plant analysis, v. 33, p. 1105-1118, 2002. Disponível em: <http://dx.doi.org/10.1081/CSS-120003875>. doi:10.1081/CSS-120003875.

LEITE, H. G.; GAMA, J. R. V.; CRUZ, J. P.; SOUZA, A. L. Função de afilamento para Virola surinamensis (Roll.) Warb. Revista Árvore, v. 30, n. 1, p. 99-106, 2006. Disponível em: <http://www.scielo.br/pdf/\%0D/rarv/v30n1/28513.pdf>.

LEITE, H. G.; BINOTI, M. L. M. S.; BINOTI, D. H. B.; FARDIN, L.; TAKIZAWA, F. I. Estimation of inside-bark diameter and heartwood diameter for Tectona grandis Linn. trees using artificial neural networks. European Journal of Forest Research, v. 130, n. 2, p. 263-269, 2011. Disponível em: <http://dx.doi.org/10.1007/s10342-0100427-7>. doi:10.1007/s10342-010-0427-7

MENDONÇA, N. P.; CARVALHO, M. C.; GOMIDE, L. R.; FERRAZ FILHO, A. C. F.; FERREIRA, M. A. Previsão de diâmetros ao longo do fuste de eucalipto via redes neurais artificiais. Enciclopédia Biofera, v. 11, n. 22, p. 2419-2429, 2015. Disponível em: <http://dx.doi.org/10.18677> doi: 10.18677.

MÜLLER, M. D.; SALLES, T. T; PACIULLO, D. S. C.; BRIGHENTI, A.M.; CASTRO, C. R. T. Equações de altura, volume e afilamento para eucaplito e acácia estabelecidos em sistema silvipastoril. Floresta, v. 44, n. 3, p. 473-484, 2014. Disponível em: <http://dx.doi.org/10.5380/rf.v44i3.33149>. doi: 
NOGUEIRA, G. S.; LEITE, H. G.; REIS, G. G. MOREIRA, A. M. Influência do espaçamento inicial sobre a forma do fuste de árvores de Pinus taeda L. Revista Árvore, v. 32, p. 855-860, 2008. Disponível em: <http://dx.doi.org/10.1590/S0100$\underline{67622008000500010}$ >. doi: 10.1590/S0100-67622008000500010

ORMEROD, D. W. A simple bole model. The Forest Chronicle, v. 49, n. 3, p. 136138, 1973. Disponível em: <http://dx.doi.org/10.5558/tfc49136-3>. doi: $10.5558 / \mathrm{tfc} 49136-3$

ÖZÇELIK, R.; DIAMANTOPOULOU, M. J.; CRECENTE-CAMPO, F.; ELER, U. Estimating Crimean juniper tree height using nonlinear regression and artificial neural network models. Forest Ecology and Management, v. 306, p. 52-60, 2013. Disponível em: <http://dx.doi.org/10.1016/j.foreco.2013.06.009>. doi: 10.1016/j.foreco.2013.06.009.

SALLES, T. T.; LEITE, H. G.; OLIVEIRA NETO, S. N.; SOARES, C. P. B.; PAIVA, H. N.; SANTOS, F. L. Modelo de clutter na modelagem do crescimento e produção em sistemas de integração lavoura-pecuária-floresta. Pesquisa Agropecuária Brasileira, v. 47, n. 2, p. 253-260, 2012. Disponível em: $<$ http://dx.doi.org/10.1590/S0100-204X2012000200014>. doi: 10.1590/S0100$204 X 2012000200014$.

SCHIKOWSKI, A. B.; DALLA CORTE, A. P.; SANQUETTA, C. A. Estudo da forma do fuste utilizando redes neurais artificiais e funções de afilamento. Pesquisa Florestal Brasileira, v. 35 , n. 82, p. 119-127, 2015. Disponível em: <http://dx.doi.org/10.4336/2015.pfb.35.82.867>. doi: 10.4336/2015.pfb.35.82.867.

SILVA, M. L. M.; BINOTI, D. H. B.; GLERIANI, J. M.; LEITE, H. G. Ajuste do modelo de Schumacher e Hall e aplicação de redes neurais artificiais para estimar volume de árvores de eucalipto. Revista Árvore, v. 33, n. 6, p. 1133-1139, 2009. Disponível em: <http://dx.doi.org/10.1590/S0100-67622009000600015>. doi: 10.1590/S010067622009000600015

SILVA, F.; CORTE, A. P. D.; SANQUETTA, C. R. Equações de afilamento para descrever o volume total do fuste de Pinus caribaea var. hondurensis na região do Triângulo Mineiro. Scientia Forestalis, v. 39, n. 91, p. 367-376, 2011. Disponível em: <http://www.ipef.br/publicacoes/scientia/nr91/cap09.pdf>.

SILVEIRA, D. P.; LEITE, H. G.; SILVEIRA, V. P.; MELIDO, R. C. N. Classificação de árvores de eucalipto para postes em sistemas agroflorestais. Revista Árvore, v. 35, n. 4, p. 875-872, 2011. Disponível em: <http://dx.doi.org/10.1590/S0100$\underline{67622011000500013}$ >. doi:10.1590/S0100-67622011000500013

SOARES, F. A. A. M. N.; FlÔRES, E. L.; CABACINHA, C. D.; CARRIJO, G. A.; VEIGA, A. C. P. Recursive diameter prediction and volume calculation of Eucalyptus trees using multilayer perceptron networks. Computers and Electronics in Agriculture, v. 78, n. 1, p. 19-27, 2011. Disponível em: < http://dx.doi.org/10.1016/j.compag.2011.05.008>. doi: 10.1016/j.compag.2011.05.008 
SOUZA, A. N.; OLIVEIRA, A. D.; SCOLFORO, J. R. S.; MELLO, J. M.; CARVALHO, L. M. T. Modelagem de rendimento no desdobro de toras de Eucalipto cultivado em sistema agroflorestal. Cerne, v. 13, p. 222-238, 2007. Disponível em: $<$ http://biblat.unam.mx/pt/revista/cerne/articulo/modelagem-do-rendimento-nodesdobro-de-toras-de-eucalipto-cultivado-em-sistema-agroflorestal>.

STATSOFT, I. N. C. Statistica (data analysis software system), version 13. Tulsa, USA, $\quad$ v. $150, \quad 2016.2$ Disponível em: $<$ http://www.statsoft.com/Products/STATISTICA/Product-Index>.

VALE, R. S.; COUTO, L.; SILVA, M. L.; GARCIA, R.; ALMEIDA, J. C. C.; LANI, J. Análise da viabilidade econômica de um sistema silvipastoril com eucalipto para a Zona da Mata de Minas Gerais. Agrossilvicultura, v. 1, n. 2, p. 107-120, 2004. Disponível em: $<$ http://www.do.ufgd.edu.br/gesaf/arquivos/docs/a artigos hp/safate2010/periodicos/ Laercio01-SBAG-v1-n2-2004-107-120.pdf>.

VENDRUSCOLO, D. G. S.; DRESCHER, R., SOUZA, H. S.; MOURA, J, P. V. M.; MAMORÉ, F. M. D.; SIQUEIRA, T. A. S. Estimativa da altura de eucalipto por meio de regressão não linear e redes neurais artificiais. Revista Brasileira de Biometria, v. 33, n. 4, p. 556-569, 2015. Disponível em: $<$ http://dx.doi.org/10.13140/RG.2.1.1742.5684>. doi: 10.13140/RG.2.1.1742.5684. 